\title{
BRASIL E MERCOSUL: rumos da integração na lógica do neodesenvolvimentismo (2003-2014)
}

\author{
Albene Miriam Menezes Klemi* \\ Roberto Goulart Menezes * *
}

\begin{abstract}
Este artigo examina o processo de integração na América do Sul sob as premissas do neodesenvolvimentismo liderado pelo Brasil, no período de 2003 a 2014. Esse giro à esquerda vem acompanhado da preocupação com o crescimento econômico com justiça social, da defesa da integração regional sob as premissas pós-neoliberais, da inserção internacional com certo grau de autonomia e do revigoramento do papel do Estado para alcançar esses propósitos. A linha de abordagem do tema considera também a presença chinesa na região, particularmente sua aproximação com a Argentina e o Brasil. Objetiva-se apresentar subsídios para o esclarecimento das seguintes questões: essa estratégia de integração liderada pelo Brasil, em que pese a defesa da integração, alcançou intensificá-la? E qual o lugar da integração no giro à esquerda? A análise do tema pauta-se em documentos oficiais e na literatura especializada, numa perspectiva histórica.

Palavras-CHave: Mercosul. Integração regional. Neodesenvolvimentismo. Pós-neoliberalismo. China.
\end{abstract}

\section{INTRODUÇÃO}

A primeira década do século XXI, na América do Sul, foi marcada pela vitória de plataformas políticas críticas ao neoliberalismo, que conformaram o chamado giro à esquerda, abrindo um novo horizonte de possibilidades políticas, econômicas e sociais. Sabemos que esse giro foi parcial e, em alguns casos, representou poucas mudanças com as políticas do Consenso de Washington que dominaram a paisagem política e econômica da América Latina nos anos noventa (Ayerbe, 2008). Governos de centro-esquerda eleitos a partir de 1998 (Venezuela, Argentina, Brasil, Equador, Bolívia) compartilham a preocupação com a justiça social, a defesa da integração regional e mais autonomia em relação aos Estados Unidos (Fiori, 2007).

\footnotetext{
* Universidade de Brasília (UnB). Departamento de História. ICC Norte, Mezanino, Campus Darcy Ribeiro, Asa Norte Cep: 70.910-900. Brasília - Distrito Federal - Brasil. albene@unb.br

** Universidade de Brasília (UnB). Instituto de Relações Internacionais.

Campus Universitário Darcy Ribeiro Caixa Postal: 04306, Cep: 70904-970. Brasília - Distrito Federal - Brasil. rgmenezes@gmail.com
}

$\mathrm{Na}$ integração regional, a perspectiva mudou do regionalismo aberto para premissas pós-liberais e ou anti-hegemônicas, com a busca do revigoramento do papel do Estado frente ao mercado para alcançar o desenvolvimento econômico e a superação da pobreza pela via do neodesenvolvimentismo.

Este artigo analisa o processo de integração sul-americana, com ênfase no Mercado Comum do Sul (Mercosul), sob a égide do neodesenvolvimentismo, no período de 2003 a 2014. Nesse período, os governos de centro-esquerda pautaram-se pela defesa da integração regional, orientados por políticas pós-neoliberais e pela busca de uma inserção internacional autônoma. A análise considera a presença chinesa na região, particularmente suas relações econômicas e comerciais com Argentina e Brasil.

O capital chinês desembarca na região em busca, principalmente, de matérias primas e tem explorado novos setores como o de serviços de engenharia e obras de infraestrutura. Também já se faz presente nos setores mais dinâmicos da economia. Isto é, a presença chinesa na América do Sul intensificou-se na última década. 
Diante das dificuldades de financiamento e atração de novos investimentos externos diretos, a Argentina buscou a China como sócio estratégico. A assinatura, em dezembro de 2014, do Convênio Marco de Cooperação em Matéria Econômica e de Investimentos entre os dois países concedeu acesso privilegiado aos chineses em vários setores da economia em troca de expressivos aportes financeiros ao país. Embora a aproximação mais estreita entre a China e o principal sócio do Brasil no Mercosul desperte receios e interrogações na diplomacia brasileira, o País também reforçou sua parceria estratégica com a China. A visita do primeiro ministro chinês em maio de 2015 reafirma as relações econômicas e políticas entre Brasília e Pequim como uma das prioridades da política externa brasileira desde o governo Lula da Silva. Diante desses fatos, algumas questões se colocam: a presença chinesa nos negócios e investimentos na América do Sul desde 2000 põe em risco o Mercosul? Quais os desafios que a estratégia chinesa impõe à estratégia de integração brasileira na região? O Mercosul apresenta alguma estratégia coletiva de relacionamento com a China em matéria de investimentos? Como fica a parceria estratégica entre Brasil e Argentina?

Assim, o presente trabalho pretende examinar as premissas intrínsecas da proposta o de integração regional na América do Sul no século XXI, considerando, em primeira linha,

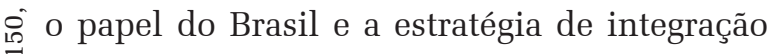
sob a lógica do neodesenvolvimentismo e da integração pós-liberal, o processo de integração face ao dinamismo do entorno regional e internacional, mormente à aliança Argentinaa China e seus impactos sobre o Mercosul e a resi levância comercial do Mercosul para o Brasil.

$\dot{0} \quad$ Objetiva-se, assim, apresentar subsídios para o esclarecimento das seguintes questões: Qual a relação entre os preceitos do neodesenvolvimentismo e a estratégia de integração liderada pelo Brasil nesse contexto? Qual o lugar da integração no giro à esquerda? A análise do tema pauta-se em documentos oficiais e na literatura especializada.

\section{O BRASIL E A INTEGRAÇÃO SUL-A- MERICANA}

A história e a dinâmica dos processos de integração na América Latina e Caribe caracterizam-se pela coexistência e interação: Mercosul, Comunidade Andina, Mercado Comum Centro Americano, Aliança Bolivariana, Aliança do Pacífico, entre outros. Isso não significa que as lógicas política e econômica que regem cada um desses processos sejam similares e que eles estejam isentos de conflitos e tensões.

Na trajetória do desenvolvimento da integração latino-americana, persistem problemas estruturais tais como baixa complementaridade econômica, baixa interdependência, assimetrias, reduzido poder infra estrutural da maioria dos Estados da região e forte dependência das economias centrais. A concentração de renda, que faz da região a mais desigual de todas, é um dos principais entraves, aliada ao baixo desenvolvimento. A tudo isso se acrescenta a crise financeira internacional de 2008, que incidiu fortemente sobre a agenda regional, com redução no crescimento das economias, aumento do protecionismo, retração nas exportações e redução dos Investimentos Externos Diretos. Apesar das adversidades e dos entraves, a integração segue no horizonte (Menezes, 2012).

No Brasil, a política externa do governo Lula da Silva (2003-2010) teve como objetivos, na América do Sul, a formação de um espaço econômico unificado, alicerçado no livre comércio e em projetos de infraestrutura, o aprofundamento da aliança estratégica com a Argentina, a revitalização do Mercosul, com a consolidação da União Aduaneira, e o aprofundamento das relações econômicas e comerciais com os países do norte da América do Sul (como o ingresso da Venezuela em 2012). Essa agenda para a região manteve-se, em linhas gerais, no primeiro governo Dilma Rousseff (2011-2014). Internamente, a política comercial do governo Dilma é fortemente cobrada pelos setores empresariais da indústria, 
com a busca por acordos substantivos. Merece destaque o empenho da presidente na busca de um acordo Mercosul-União Europeia.

Na análise de Cervo (2013), teríamos três ideias de América do Sul divergentes: a bolivariana, caracterizada pelo projeto do socialismo do século XXI e de caráter contra-hegemônico; a argentina, na qual há um projeto comercialista; e o projeto globalista do Brasil. Nenhuma das três ideias de América do Sul conseguiu aglutinar as condições para fazer avançar o processo de integração. Pelo contrário, de acordo com Cervo, o que teríamos hoje é a dispersão da integração na América do Sul. A crise econômica argentina, agravada com o impasse na resolução da queda de braço com um grupo de credores da dívida que não aceitou as condições determinadas pelo governo argentino, bem como a crise política e econômica da Venezuela pós-Chávez dificultam o processo de integração.

Enquanto, na América do Sul, o processo de integração patina, a estratégia dos Estados Unidos ganha impulso com a Parceria TransPacífico, mega-acordo de serviços abarcando, entre outros, ensino, telecomunicações, serviços financeiros e infraestrutura. Por outro lado, a China aumenta sua presença na região e, em especial, nos países membros do Mercosul.

Enquanto um dos componentes da identidade internacional do Brasil, a dimensão geográfica da América do Sul, sempre esteve presente no horizonte regional de sua diplomacia, desde a proclamação da República (Bueno, 2002), em termos práticos, no entanto, a tomada de consciência do Brasil quanto a se perceber como um país sul-americano deu-se de maneira lenta e em décadas recentes. Do mesmo modo, o emprego do termo América do Sul nomeia realidades geográficas distintas entre o final do século XIX e o início do século XXI (Santos, 2005).

Tanto a diplomacia do governo Lula da Silva como a do ex-presidente Fernando Henrique Cardoso sempre se reivindicaram como a favor da América do Sul e cada qual buscou fa- zer do Brasil o vetor de integração regional. A experiência do Mercado Comum do Sul (1991) assinalou o caminho da integração regional como uma das prioridades da política externa brasileira. Ele conformou um novo subsistema regional numa reação criativa para ajustar os países integrantes às transformações sistêmicas em curso desde meados da década de 1980. No plano geopolítico, a Iniciativa para as Américas, lançada em junho de 1990 pelo executivo dos Estados Unidos, foi decisiva, bem como as transformações na ordem internacional advindas do fim do bloco socialista e o fim da guerra fria.

Com a assinatura, em 2004, do acordo entre o Mercosul e a Comunidade Andina de Nações, criando uma zona de livre comércio na América do Sul, um espaço integrado irá ganhar corpo. Nas duas gestões do presidente Fernando Henrique Cardoso (1995-2002), o conceito de América do Sul firmou-se no discurso diplomático e passou a ocupar o lugar do conceito de América Latina. Em 1997, Cardoso afirmava:

\footnotetext{
Nunca acreditei na possibilidade de integração latino-americana e muito menos caribenha. Não dá. Então, na minha visão, o nosso espaço histórico-geográfico é a América do Sul [...] o espaço que nós temos que organizar é esse aqui (Sallum Jr, p. 25).
}

O primeiro encontro dos governos da região, realizado em Brasília no contexto das comemorações dos 500 anos do Brasil, fez parte dessa nova orientação. Nesse encontro, decidiu-se lançar a Iniciativa de Integração da Infraestrutura Regional Sul-Americana (Iirsa), a fim de integrar fisicamente a América do Sul por meio de 10 eixos, com a realização de obras nos setores de transportes, energia e telecomunicações.

No discurso da diplomacia do governo Lula da Silva, a América do Sul também configurou uma frente externa de primeira ordem. Segundo Amorim, a América do Sul era a principal prioridade, mas a política externa do País não pode [ria] estar confinada a uma única região, nem pode [ria] ficar restrita a uma única dimensão. 
O Brasil pode e deve contribuir para a construção de uma ordem mundial pacífica e solidária, fundada no Direito e nos princípios do multilateralismo (Amorim, 2003, p. 57).

O reforço da presença do Brasil na região e o discurso diplomático que elevou a América do Sul à condição de prioridade na agenda da nova política externa do País reacendem o debate acerca da liderança regional do Brasil no espaço sul-americano. A pesquisa desenvolvida por Souza (2009) com integrantes da comunidade brasileira de política externa mostra que, dos dezoitos grandes temas identificados, oito foram considerados de extrema importância e, desses, quatro estão relacionados à atuação do País na região: garantir a democracia na América do Sul, integrar a infraestrutura, fortalecer a liderança regional do Brasil e fortalecer o Mercosul. A União de Nações Sul-Americanas (Unasul) abriu uma frente complementar no projeto de integração sul-americano. E tem se mostrado importante no aprofundamento da confiança entre os países da região, pois, como fórum de concertação política, tem conseguido lograr êxitos, principalmente na garantia da democracia regional.

O conceito de integração que está na base da Comunidade Sul-Americana de Nações (CASA), antecessora da Unasul, é o da integração multidimensional, para além do regionalis- mo aberto proposto pela Comissão Econômica సั. para América Latina (Cepal) no começo dos in anos 1990. Por regionalismo aberto entende客 se a liberalização comercial ampla, vista como $\overrightarrow{2}$ uma etapa intermediária para a liberalização \%̊ econômica multilateral. E é por esse conceito de 㩆 integração que a Aliança do Pacífico se orienta. a O espaço significativo que a América do iิ Sul ocupou na agenda da diplomacia do go-

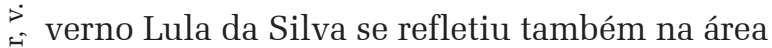
burocrática destinada a cuidar dos assuntos na região. ${ }^{1}$ No Ministério das Relações Exteriores,

${ }^{1}$ Do total de viagens realizadas ao exterior pelo presidente Lula da Silva, $30 \%$ delas foram para a América do Sul, o que somou 145 dias. A Europa com 32\% e 137 dias, África com $11 \%$ e 51 dias e a América do Norte com $10 \%$ e 47 dias. Folha de S. Paulo, 10. Set. 2010. a divisão encarregada pela região foi reforçada com a criação da Secretaria Geral para América do Sul (SGAS), que passou a reunir os Departamentos de América do Sul, Central e Caribe (DAS I e II), de Integração, de Negociações Internacionais e de México, América Central e Caribe. A criação da SGAS pode ser entendida como forte indicativo do grau de importância que a região adquiriu na última década. No início dos anos 1990, todas as questões relativas ao continente americano estavam sob a responsabilidade de um único Departamento, o das Américas.

Assim, na integração regional, passa-se a indicar a necessidade de revisão do Mercosul, sobretudo sua orientação estratégica. A mudança de percepção é geralmente chamada de regionalismo pós-liberal, pós-hegemônico. A integração não se fará apenas com comércio e economia. É preciso ir além.

Do lado argentino, de acordo com Russell y Tokatlian (2003), o governo Kirchner inaugura o paradigma da participação responsável e passa a ver no Brasil um parceiro estratégico e não somente um sócio econômico. Na declaração de Buenos Aires, Argentina e Brasil prometeram intensificar a cooperação, fortalecer os processos democráticos e de integração, aperfeiçoar as instituições do Mercosul, gerar desenvolvimento sustentável e lutar contra a pobreza.

A nova estratégia de integração posta em prática pela diplomacia brasileira teve, no resgate da parceria estratégica com Buenos Aires, um de seus pilares. A defesa de um Mercosul guiado por princípios desenvolvimentistas encontrou consenso entre dois sócios maiores do processo de integração no Cone Sul. A empreitada integracionista de Brasília-Buenos Aires, desgastada pelas divergências no modelo de integração e por frequentes atritos comerciais, foram acentuadas pela situação de penúria do quadro político, econômico e social argentino desde a crise dezembro de 2001. Refazer o Mercosul e utilizá-lo como plataforma para estendê-lo a toda a região tem sido o principal esforço do governo brasileiro. 


\section{INTEGRAÇÃO REGIONAL E A LÓGI- CA DO NEODESENVOLVIMENTISMO}

O giro à esquerda na América do Sul com um projeto de integração calcado na implantação de políticas neodesenvolvimentistas e pós-liberais, como de largo conhecimento é antecedido pela escalada do neoliberalismo no mundo e na região, assim como pelo fenômeno da globalização. O impacto negativo do transcurso dessa fase do neoliberalismo, nas sociedades de vários países sul-americanos, abriu espaço para outra agenda integracionista neodesenvolvimentista.

Por outro lado, o fim da Guerra Fria afasta do horizonte as opções estratégicas até então com apelo na América Latina, a exemplo da proteção extra-hemisférica, da unidade coletiva, da revolução social e do terceiro-mundismo, como ressaltam Russell e Tokatlian (2008). Extinta a bipolaridade, registra-se, tanto no plano global como no regional, grande ativismo em matéria de acordos preferenciais de comércio, onda batizada como novo regionalismo, caracterizado pela abertura dos mercados e assinatura de tratados de criação de áreas de livre comércio e blocos regionais entre parceiros de notáveis assimetrias (Bouzas et. al, 2008).

Segundo Diniz, “[...] os anos 1990 representaram um corte na trajetória do capitalismo brasileiro, cujo cerne seria a ruptura com o nacional-desenvolvimentismo" (2011, p. 493). A escalada do globalismo neoliberal, a partir dos anos 1980, leva à formulação do chamado Consenso de Washington (1989), transformado em política oficial do Fundo Monetário Internacional (FMI) em 1990. Nos anos noventa, os países da América do Sul, endividados e com graves crises econômicas, sob pressão, se submeteram às suas premissas e implementaram uma agenda pública sustentada em uma estratégia de desenvolvimento calcada na ortodoxia liberal. No caso do Brasil, como observa Diniz, a execução dessas diretrizes, "[...] considerando-se o desempenho da economia em seu conjunto, os resultados foram medíocres” (Diniz, 2011, p. 498).
As políticas neoliberais dos anos 1990 preconizavam a busca do desenvolvimento nacional pela trilha da integração atrelada à economia globalizada, pela ampliação da desnacionalização da economia, pelas privatizações, juros altos e abertura econômica. Elas provocaram o fenômeno que uma corrente de interpretação historiográfica chama de o desmonte da nação e do Estado (Lesbaupin, 1999; Biondi, 2014). Esse fenômeno foi envolto em um paradoxo: o Estado, que claramente abdica de interferir na economia, é altamente interventor no afã de legislar desregulamentando a economia para aumentar os espaços do mercado (Boschi; Gaitán, 2008). Bresser-Pereira observa,

A oposição entre Estado e mercado é uma agenda
neoliberal que só se tornou um problema do nosso
tempo na medida em que, nos anos 1980 e 1990, o
neoliberalismo se tornou de tal forma hegemônico
que essa agenda parecia ser natural e legítima. Por
meio dessa oposição, duas instituições foram colo-
cadas no mesmo plano que, por sua própria nature-
za, são estruturalmente complementares nas socie-
dades modernas (2009; p. 7).

Não é por acaso, portanto, que a primeira década do século XXI assistiu, no âmbito acadêmico, a uma retomada do pensamento crítico em relação ao chamado neoliberalismo. Para Diniz, “[...] o período 2002-2008 notabilizou-se pelo fortalecimento do pensamento crítico e pela procura de uma redefinição de rumos no que se refere às propriedades da agenda pública." (2011, p. 498). Autores como Há-Joon Chang, Joseph Stiglitz, Amartya Sen, dentre outros, embora divergindo em muitos aspectos, esposaram o pensamento crítico, levantaram argumentos e apontaram dados em contraposição à globalização e ao neoliberalismo como via para decolar o desenvolvimento dos países periféricos (Diniz, 2011). Paralelamente, outros segmentos sociais, mormente dos países sob o impacto do neoliberalismo, participaram do debate crítico, com destaque para intelectuais, políticos, sindicalistas e movimentos sociais.

No Brasil, particularmente desde o final 
do governo Fernando Henrique Cardoso (19952002), as críticas aos postulados neoliberais intensificaram-se. Assim, muitas narrativas de acadêmicos, a partir da análise e interpretação da realidade histórica da América Latina de um modo geral, e da América do Sul e do Brasil de forma mais específica, tentam apontar caminhos, sumariar e considerar as transformações que se processam na região como um novo desenvolvimentismo. Desse modo, muitos intelectuais, com destaque para Luiz Carlos Bresser-Pereira, João Sicsú, Luiz Fernando de Paula, Renaut Michel, Luiz Gonzaga Beluzzo, Daniela Prates e Ricardo Bielschowsky, não só criticam o antigo nacional-desenvolvimentismo e o neoliberalismo, como preconizam um novo desenvolvimentismo (Diniz, 2011). Novo em relação ao desenvolvimentismo dos anos cinquenta e novo por supor nova abordagem teórica e novas características. Dentre outras características, novo por considerar nova estratégia de desenvolvimento com crescimento econômico impulsionado em boa medida pelo fortalecimento do mercado interno de consumo de massa e desenvolvimento social. Ponto convergente desses estudos, de alguma forma, vem a ser a metodologia aplicada. Em linhas gerais: identificam-se novas características a partir das circunstâncias históricas e dos interesses políticos, econômicos e sociais das agendas governamentais; estabelecem-se comparações com o antigo desenvolvimentismo, com as políticas do Consenso de Washington e com o pensamento ortodoxo convencional.

Historicamente, a ascensão ao poder de Hugo Chávez na Venezuela, como presidente democraticamente eleito, em 1998, marca o início do giro à esquerda na América do Sul, com uma agenda de integração nos marcos de um novo desenvolvimentismo. Sequencialmente, chegaram ao poder outros sete políticos com perfil de esquerda e nacionalistas - os presidentes Luiz Inácio Lula da Silva (Brasil) e Nestor Kirchner (Argentina) em 2003; Tabaré Vázquez (Uruguai), em 2005; Michelle Bachelet (Chile) e Evo Morales (Bolívia) em 2006;
Rafael Correa (Equador), em 2007; e Fernando Lugo (Paraguai) em 2008 -, todos democraticamente eleitos. Ademais, essas eleições vêm adornadas de um enorme peso político e simbolismos regionais, já que ascenderam ao poder um militar esquerdista, um operário, um peronista nacionalista, uma mulher filha de um militar perseguido pela ditadura chilena e um líder indígena.

As estratégias de atuação desses governos se aproximam de alguma forma, em torno da integração regional e de um novo intervencionismo. Desse modo, eles tomam iniciativas no sentido de alargar e aprofundar a integração no subcontinente e de implementar projetos de crescimento econômico com desenvolvimento social, com maior presença do Estado na regulação da economia. Essas iniciativas apresentam características inerentes às especificidades de cada país, mas, de um modo geral, preservam várias políticas neoliberais em um novo modelo de intervenção. Os governos dos aludidos chefes de Estado vão se preocupar com a questão social e o fortalecimento das economias nacionais. Nesse sentido, adotam políticas públicas de transferência de renda e gastos públicos mirando o fortalecimento dos mercados internos.

Desse modo, dos doze países independentes da América do Sul, oito compõem um grupo que passou a aplicar políticas econômicas chamadas de neodesenvolvimentistas. Esses governantes formam uma constelação de representantes de uma esquerda moderada, que tenta conciliar preceitos neoliberais com intervencionismo, para dinamizar o crescimento econômico, ao tempo que introduzem políticas sociais para atenuar a situação das camadas sociais discriminadas pela secular concentração de poder e renda, tão típica da América Latina. Afastavam-se assim, de alguma forma, da ortodoxia neoliberal. Desse modo, a utilização do termo neodesenvolvimentismo tem sido comum em parte da literatura para caracterizar alguns governos da América do Sul associados ao giro à esquerda ocorrido na 
região, na primeira década do século XXI. O principal ponto é o revigoramento da capacidade do Estado, comprometida pelas políticas neoliberais que dominaram a paisagem política e econômica nos anos 1980 e 1990. Com isso, os governos neodesenvolvimentistas afastamse, de alguma forma, de muitos postulados dos

Representantes das agências de Bretton Woods, que introduziram noções como a de ajuste, disciplina fiscal e governabilidade, assentadas em uma concepção instrumental da política e numa visão tecnocrática e liberal de desenvolvimento associada unicamente com o crescimento da economia e do mercado e o deslocamento progressivo do Estado para um papel menor na economia (Lima, 2009, p. 78).

Desde o início do novo milênio, novas coalizões de poder, eleitas sob a bandeira de uma agenda pós-neoliberal na região, buscaram recolocar a necessidade da justiça social com políticas públicas de combate à pobreza, fortalecimento da soberania nacional e mais autonomia em suas políticas externas. Para isso, o revigoramento da capacidade dos Estados e uma compreensão melhor da complementaridade entre eles e os mercados marcam as estratégias de desenvolvimento da região desde então, ainda que de modo não homogêneo (Rodrik, 2002). O neodesenvolvimentismo, portanto, representa a capacidade de cada país articular suas instituições em prol do crescimento econômico, mormente o aumento da renda nacional, e melhorar os condicionantes de bem-estar social (Boschi; Gaitán, 2008).

Assim, em linhas gerais, em um esforço de síntese e de reatualização das premissas nas quais se assenta o novo desenvolvimentismo, pode-se dizer que ele busca o fortalecimento do protagonismo do Estado intervencionista. Trata-se de um intervencionismo voltado para dar ânimo ao mercado interno e à distribuição de renda, impulsionar a dinâmica democrática, propondo e aprovando um escopo legislativo e "[...] aparatos administrativos com a capacidade e o poder de fazê-las cumprir" (Boschi; Gaitán, 2008, p. 306). Difere do tradicional desenvolvimentismo em vários aspectos, com destaque para o não retorno à participação estatal diretamente no setor produtivo.

Não obstante, algumas interpretações dessa realidade são mais críticas, como as ponderações de Diniz (2013), para quem o Brasil não vive um modelo desenvolvimentista no sentido forte desse termo e responde com reticências sua indagação: “[...] ao término da primeira década do terceiro milênio, é possível dizer que existe um novo modelo de desenvolvimento no Brasil?” (2013, p. 10). Segundo a autora,

[...] alguns analistas acreditam poder identificar, ao longo da última década, a configuração de uma nova perspectiva de desenvolvimento. Esta consiste na articulação do crescimento com distribuição de renda, destacando-se ainda a redução da vulnerabilidade externa, o equilíbrio macroeconômico, a democracia e a inserção internacional competitiva sob o primado de uma nova visão da soberania nacional. (2013, p. 11)

\section{Todavia,}

[...] não é possível identificar um projeto de longo prazo aglutinador de maneira consistente das diversas dimensões de conceito. [...] O que se tem é, ao contrário, o reforço de um paradigma produtivo do passado que deveria perder força paulatinamente com a mudança da matriz energética de acordo com as novas exigências de redução dos índices das emissões de CO2 (dióxido de carbono). (Diniz, 2013, p. 10-11)

Assim, o governo Lula da Silva buscou destravar o capitalismo brasileiro, por meio do desenvolvimento com inclusão social, com a retomada em grande parte do "[...] velho projeto desenvolvimentista que remonta à década de 1930 e que só foi interrompido nos anos 1990" (Fiori, 2007, p. 259).

No plano da integração regional, os defensores do paradigma neodesenvolvimentista vêm-se confrontados com as condicionantes limitadoras impostas pela nova ordem mundial da chamada globalização, com a emergência de mecanismos decisórios descentralizados multilaterais. Hoje, um dos maiores desafios é o Trade in Services Agreement (TISA), Acordo Geral de Serviços, uma iniciativa dos Estados 
Unidos e União Europeia. O TISA envolve cinquenta países e corresponde a cerca de $70 \%$ de todos os serviços do mundo. Segundo documentos divulgados pelo WikiLeaks, publicados em seis de junho do corrente ano, o acordo atará as mãos e os pés dos Estados com a proposta de lista negativa (os países apresentam uma lista dos serviços que pretendem deixar de fora do acordo), proibição de normas nacionais e cláusula para o futuro (como a lista é negativa, futuros serviços, hoje inimagináveis, estarão automaticamente incluídos). O acordo elimina todos os controles e obstáculos para a liberalização global dos serviços. Na lista dos participantes do processo negociador, estão México, Costa Rica, Panamá, Colômbia, Peru, Paraguai e Uruguai e Chile, ou seja, os mais importantes países da costa do Pacífico da América Latina, dos quais três da América do Sul e dois do Mercosul.

Por outro lado, a perspectiva da integração regional sob a lógica do neodesenvolvimentismo desenha-se no subcontinente sob uma presumida liderança do Brasil, avaliada por Lima como do tipo empresarial, que corresponde a um contexto onde

[...] la voluntad política de los gobernantes y que no necesariamente tienen implicaciones desde el punto de vista de los grados de compromiso y obligación asumidos o de su implementación doméstica (2008, p. 93).

O Brasil busca formar um bloco que possibilite a seus membros reunir maior poder de negociação nos fóruns e organismos internacionais e maior grau de autonomia frente às 될 relações com a potência hegemônica mundial, \& os Estados Unidos, e outros parceiros de grano de poder, como a União Europeia e a China. As $\therefore$ iniciativas nesse sentido diferenciam-se das propostas norte-americanas implementadas na América do Norte North American Free Trade Agreement (NAFTA), na América Central a Dominican Republic America Free Trade Agreement (CAFTA-DR), além dos acordos bilaterais de livre comércio assinados com países da re- gião. O futuro imediato dirá como vai se conformar o concerto da integração sul-americana sob a liderança do Brasil, com países membros do próprio Mercosul participando do TISA, no momento em processo de negociação.

A integração sob a lógica neodesenvolvimentista pressupõe tanto uma integração econômica como uma integração dos povos. Observa-se, entre os principais atores que a conduzem, certo grau de convergência política e ideológica, bem como propensão ao diálogo. Em jogo está a construção de um espaço sul-americano integrado na seara econômica, física, social e de segurança. O mapa desse espaço inclui regiões geográficas do porte do Geocentroplatino, Chaco-Pantanal, Amazônia e Amazônia Azul.

Para pôr em prática esse intento, foram criados, no período em foco, instituições políticas e comunitárias, assim como mecanismos de segurança e financeiros, com destaque para a Unasul, em 2008, voltada para fortalecer as relações comerciais, culturais, políticas e sociais dos dozes países independentes da América do Sul. No mesmo ano, foi instituído o Conselho de Defesa Sul-Americano (CDS), pela Cúpula extraordinária da Unasul. Em 2010, foi assinado protocolo adicional à Unasul sobre compromisso democrático. Anteriormente, veio a lume o Fundo para a Convergência Estrutural e Fortalecimento Institucional do Mercosul (Focem), datado de 2004 e estabelecido em 2005 com o objetivo de aprofundar o processo de integração regional por meio da redução das assimetrias. Assentado na legislação brasileira por meio do Decreto N. 5.969 da Presidência da República, de 21 de novembro de 2006, ele prevê, em seu Art. 2, o desenvolvimento de quatro programas: Convergência Estrutural, Desenvolvimento da Competitividade, Coesão Social e Fortalecimento Institucional e do Processo de Integração. Ainda no ano de 2007, teve início o funcionamento do Parlamento do Mercosul (Parlasul), órgão legislativo consultivo dos povos do Mercosul. Em 2010, foi instalada a Universidade de Integra- 
ção Latino-Americana (Unila). Menciona-se ainda o estabelecimento da livre circulação de pessoas sem necessidade de visto, exceto para a Guiana Francesa.

Sem dúvida, são iniciativas de certo porte. Mas até que ponto elas são suficientes para promover a coesão dos países da região sob um mesmo projeto integracionista? Em sua historicidade, essa pergunta será em parte respondida pelo posicionamento dos países da região frente às iniciativas da China e dos Estados Unidos, em primeira linha. Tais iniciativas abrem oportunidades e delineiam limites ao desenho pósneoliberal, após o Consenso de Washington, e o desenvolvimento da integração regional.

\section{A CHINA E A INTEGRAÇÃO NA AMÉRICA DO SUL}

Em menos de uma década e meia, a China se transformou em um destino crucial para os produtos primários da América Latina e já ocupa a posição de primeiro ou segundo parceiro comercial em diversos países da região. Em 2013, cerca de 80\% das exportações da região para o mercado chinês se concentrou em cinco produtos primários (petróleo, cadeia da soja, minério de ferro, cobre e açúcar), o que significa um aumento expressivo em relação aos $47 \%$ exportados em 2000. De acordo com a Cepal, isso evidencia [...] el fuerte proceso de reprimarización que ha tenido lugar desde entonces (2015, p. 43).

A principal explicação para o forte incremento das relações comerciais entre a China e a América Latina é o crescimento econômico chinês que, entre 2000 e 2011, foi de $10 \%$ ao ano. Com os desdobramentos da crise internacional de 2008, o crescimento chinês desacelerou e, com isso, a demanda por matérias primas observada na primeira década do século XXI também. ${ }^{2}$

${ }^{2}$ Sérgio Lamucci. Queda das commodities obriga AL a avançar em outras áreas, diz Bird. Valor Econômico, 20. maio. 2015, p. A11.
Entretanto, a intensificação da presença dos negócios chineses na América Latina, em especial na América do Sul, tem recebido reações distintas de analistas e estudiosos. De um lado, estão os que consideram as relações econômicas e comerciais entre China e América Latina como complementares e, portanto, mutuamente benéficas. Por outro, estão os que realçam as assimetrias econômicas e a reprimarização da pauta exportadora, conformando uma nova dependência (Ferchen, 2011; Jenkis, 2015). Vejamos os principais argumentos de cada uma delas.

A presença da China nos negócios e investimentos na América Latina, em especial na América do Sul, enseja duas visões mais evidenciadas. A otimista tende a valorizar a relação de complementaridade, pois o aumento da demanda chinesa por matérias primas contribui para o desenvolvimento dos países da região. Já a visão pessimista assinala que a China representa uma ameaça às exportações de produtos manufaturados do Sul (Jenkis, 2015). Estaria havendo uma reedição da conhecida relação centro-periferia, dessa vez em relação à China.

O estudo da Cepal (2015) acerca da cooperação econômica entre a América Latina e China deixa bem clara a dependência da região do mercado chinês para a exportação de produtos primários. Já a China vende para os países latino-americanos manufaturas de alta, média e baixa tecnologia, conforme se pode verificar no Gráfico 1.

Os dados de 2013 parecem dar razão à visão pessimista acerca das relações entre China e América Latina. Mesmo o Brasil, a principal economia da América Latina e Caribe, detentor de um parque industrial diversificado, também sofre (assim como o México) com a concorrência das manufaturas chinesas. Em artigo publicado em 2007, Castro destacava a necessidade de políticas públicas inovadoras e novas estratégias necessárias para o Brasil lidar com as oportunidades e desafios representados pela ascensão chinesa na economia global, o que deslocou, segundo esse autor, o centro de 


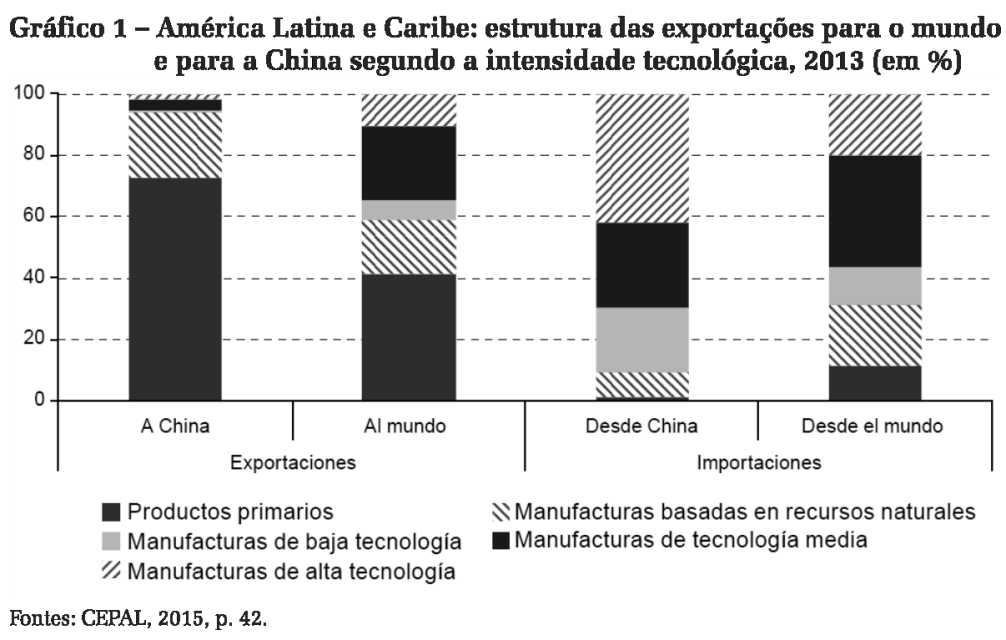

gravidade do crescimento econômico mundial para a Ásia. Diante da avassaladora indústria chinesa, acrescenta Castro, caberiam três políticas: proteção (de modo residual), apoio ao reposicionamento (presença significativa) e a busca pelo futuro (dominante).

Tanto o ex-presidente Lula da Silva como a presidente Dilma Rousseff, ao mesmo tempo em que exaltam a parceria estratégica (ou o sócio estratégico, na denominação dos chineses), mostram-se preocupados com a assimetria econômica e comercial e a baixa presença de produtos de maior valor agregado nas compras da China oriundas do País.

Em 2004 durante visita à China, o então presidente Lula da Silva (2003-2010) observou:

O Brasil não quer continuar sendo um mero exportador de soja e minério de ferro. Nós chegaremos a atingir a perfeição na relação comercial com a China quando estivermos exportando e importando conhecimento, quando estivermos exportando e importando tecnologia de ponta, quando estivermos ajudando, numa atuação conjunta, a mudar as regras da Organização Mundial do Comércio. (Lula da Silva. Xangai, 26 de maio de 2004).

Desde então, o embarque de produtos primários do Brasil para a China cresceu e o quadro pouco se alterou em favor dos produtos manufaturados brasileiros, em que pese a presença quase solitária da Empresa Brasileira de Aeronáutica S.A. (Embraer) no mercado chinês. Tanto é assim que a presidente Dilma
Rousseff, sete anos depois, voltou a insistir na necessidade de uma relação mais equilibrada entre as duas economias:

Precisamos ir além da complementaridade de nossas economias, apesar da complementaridade ser importante. E precisamos ir além dessa complementaridade para favorecer uma relação mais dinâmica, mais diversificada e mais equilibrada. A transformação da pauta em direção a produtos mais intensivos em tecnologia é o grande desafio da economia brasileira nos próximos anos e um dos pilares para o crescimento sustentado do nosso comércio exterior. As exportações brasileiras para a China ainda estão excessivamente concentradas em produtos como soja, minério de ferro, petróleo e celulose. Isso é bom, mas não é o bastante. São todos produtos importantes, cuja exportação queremos incrementar, agregando a eles valor. É necessário, no entanto, diversificá-los para que a expansão do comércio bilateral seja sustentável. A diversificação também envolve presença de produtos de maior valor agregado (2011).

O descontentamento da presidente Rousseff com a relação desequilibrada no comércio com a China tem sido explicado principalmente por perda de competitividade da indústria brasileira, baixa inovação das empresas do País, além do câmbio artificial mantido pelo governo chinês. Em 2014, somente Brasil, Chile e Venezuela apresentaram superávit comercial com a China, conforme é demonstrado no Gráfico 2.

No Gráfico 2, entre os países membros do Mercosul, somente Brasil e Venezuela apresentaram superávit comercial no comércio com a China. Paraguai (que não mantém relações diplomáticas com a República Popular da China, e sim com Taiwan), Argentina e Uruguai tiveram déficit. Cabe destacar que o México registrou o maior déficit em 2014; ao contrário dos demais países da América do Sul, esse país não tem o setor primário como carro-chefe de suas exportações para o mercado chinês, e sim o setor manufatureiro. 
Gráfico 2 - Países da América Latina e Caribe: saldo comercial com a China, 2014 (em milhões de dólares)

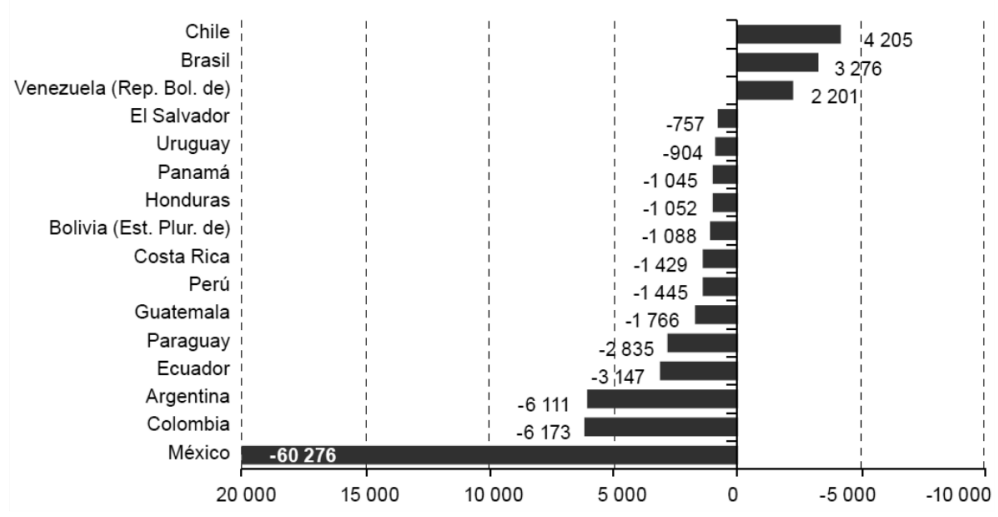

Fontes: CEPAL, 2015, p. 42.

A tendência indica que a China aumentará sua presença comercial e econômica na América Latina e Caribe. Os dados da tabela a seguir mostram como as recentes e intensas relações comerciais da China com a América Latina e Caribe cresceram na última década e meia. Em 2000, cerca de 1\% de produtos eram comprados e exportava-se quase nada para cá. Uma década depois, esse percentual já estava perto de 10\%; e está projetado, para 2020, a ultrapassagem de um parceiro tradicional, que é a União Europeia.

Em que pese a crescente importância da China no comércio com a América Latina, os Estados Unidos continuam sendo um parceiro fundamental para o conjunto da região, mesmo com a redução do dinamismo de sua economia após a crise de 2008.

Para a China, os principais mercados são a Ásia, a União Europeia e os Estados Uni-

Tabela 1 - América Latina e Caribe: participação dos Estados Unidos, Uniâo Europeia e China no comércio total da região, 2000-2020 (em \%)

\begin{tabular}{|c|c|c|c|}
\hline & 2000 & 2009 & 2020 \\
\hline \multicolumn{4}{|l|}{ Importaciones } \\
\hline Est ados Unidos & $51 \%$ & $33.1 \% \downarrow$ & $26.1 \% \downarrow$ \\
\hline Unión Europea & $14 \%$ & $14.7 \% \uparrow$ & $14 \% \downarrow$ \\
\hline China & Alrededor del 1\% & $9.5 \% \uparrow$ & $16.2 \% \uparrow$ \\
\hline \multicolumn{4}{|l|}{ Exportaciones } \\
\hline Estados Unidos & $60 \%$ & $38.6 \% \downarrow$ & $28.4 \% \downarrow$ \\
\hline Unión Europea & $12 \%$ & $13.8 \%$ & $13.6 \% \downarrow$ \\
\hline China & Cercano a cero & $7.6 \% \uparrow$ & $19.3 \% \uparrow$ \\
\hline
\end{tabular}

Fonte: Laneydi Martínez. Anuario de integración, 10. 2014, p. 86. Elaborado pela autora a partir de dados da CEPAL (2011). dos. A parcela ocupada pela América Latina é pequena, quando comparada a essas outras três regiões e países. Já para os países da região, sobretudo os da América do Sul, o comércio com a China se mostra fundamental: do total de bens exportados para a China pela região em 2014, o Brasil enviou 42,6\% (US\$ 40,6 bilhões), seguido pelo Chile com 19,4\% (US\$ 18,4 bilhões), Venezuela 10,8\% (US\$ 10,3 bilhões), Peru 7,3\% (US\$ 6,9), México 6,3\% (US\$ 5,9), Colômbia 5,9\% (US\$ 5,6 bilhões) e Argentina 4,9\% (US\$ 4,6 bilhões). Do total de bens exportados pela América Latina e Caribe para o mercado chinês, esses sete países exportaram $97,2 \%$, ou seja, as relações comerciais com a China não abrangem, com a mesma intensidade, a região como um todo. Descontando a participação do México, a América do Sul responde por 91\% do total (CEPAL, 2015).

Fonte de vultosos recursos em potencial (Banco Asiático de Investimento em Infraestrutura, criado em 2015, com participação de cerca de $40 \%$ do Novo Banco dos Brics - Brasil, Rússia, China, Índia e África do Sul, que começou a funcionar em julho de 2015, fundo soberano, entre outros), a China é tida como um parceiro vital, sobretudo para os países da América do Sul. O recente convênio firmado pela Argentina com o governo chinês é um exemplo. Em dezembro de 2014, a presidente Cristina Kirchner firmou o Convênio Marco de Cooperação em Matéria Econômica e de Investimentos (aprovado em regime de urgência pelo Parlamento), que concede acesso privilegiado aos investidores chineses a vários setores da economia em troca de sun- 
tuosos aportes financeiros.

Esse convênio aprofunda as relações sino-argentinas no contexto das dificuldades de financiamento internacional advindas da batalha judicial travada pelo país com um pequeno e poderoso grupo dos investidores que não aceitaram as condições impostas pelo ex-presidente Nestor Kirchner (2003-2006) na reestruturação da dívida externa argentina. Embora esse estreitamento das relações sino-argentino desperte receios e interrogações na diplomacia brasileira, o País também tem envidado esforços para aprofundar suas relações econômicas e políticas com a China, como, por exemplo, através dos Brics.

Uma das preocupações com a presença chinesa na região é acerca dos possíveis efeitos sobre o Mercosul. Ainda quando a China não representava percentual significativo no intercâmbio comercial dos países membros, na XXVI Reunião do Conselho Mercado Comum, realizada em julho de 2004 em Puerto Iguazú, os presidentes

[...] reafirmaram sua vontade de aprofundar as relações econômicas e comerciais entre o MERCOSUL e a República Popular da China. Nesse sentido, congratularam-se com a realização em Pequim do V Diálogo entre ambas as partes, no qual se conformou o Grupo Enlance MERCOSUL-China e se decidiu iniciar um estudo de viabilidade de um eventual acordo comercial (MRE, 2004, p. 307).

ค Desde então, o Mercosul não parece ter definido uma estratégia coletiva para relacionar-se com o gigante chinês. Ferrer (2015) chama a atenção para esse ponto central: os membros do Mercosul necessitam concertar suas políticas para a China. Diante da presença chinesa nos negócios e investimentos na América do Sul na última década, qual a capacidade do Mercosul como ator político e econômico? Será que a estratégia chinesa pode erodir a base de sustentação do Mercosul?

Os conflitos da Argentina com os sócios do Mercosul, desde a crise econômica de 2001, acumulam-se. A crise econômica argentina deixou pouca margem para a diplomacia de
Buenos Aires incrementar o processo de integração no curto prazo. A perda de competitividade da economia do país redundou em novas medidas unilaterais contra as exportações brasileiras, ferindo, ainda mais, a combalida Tarifa Externa Comum (TEC).

Em nome da preservação da parceria estratégica com Buenos Aires, o governo brasileiro aceitou novas exigências argentinas no plano comercial, entre as quais a adoção da Cláusula de Adaptação Competitiva, o que gerou novas reclamações e descontentamento do empresariado brasileiro. No caso do Mercosul, sequer a união aduaneira está completa, o que acarreta o adiamento do fortalecimento do acordo regional. O Itamaraty ressalta que é preciso encarar as dificuldades políticas e econômicas dos países vizinhos sob a ótica da não indiferença e do princípio da solidariedade.

Tanto no Brasil como na Argentina, o capital chinês tem se expandido para setores mais dinâmicos da economia. Na visita do PrimeiroMinistro Li ao Brasil, em 19 de maio de 2015, novamente o setor da infraestrutura dominou as atenções. A presidente Rousseff e seus ministros da Fazenda e o do Planejamento enumeraram as oportunidades de investimento no setor ao mandatário e aos integrantes de sua comitiva. A recepção ao Primeiro-Ministro chinês ocorreu pouco tempo após o retorno da presidente da República à Europa, onde esteve para o encontro de Cúpula da Comunidade de Estados Latino Americanos e Caribenhos (Celac) - União Europeia, e antes da visita aos Estados Unidos. Em sua extensa agenda no continente europeu, a presidente atualizou seus interlocutores da União Europeia acerca das negociações do Mercosul no fechamento da oferta aos europeus para a formação de uma área de livre comércio birregional, reafirmado na $48^{\mathrm{a}}$ Cúpula do Mercosul realizada em Brasília, em julho de $2015 .^{3}$

${ }^{3}$ No item 29 da Declaração, os presidentes "Destacaram os entendimentos alcancados durante a Reunião Ministerial MERCOSUL- União Europeia, em 11 de junho de 2015, em Bruxelas, e reiteraram seu compromisso de realizar a troca de ofertas de acesso a mercados entre os dois blocos no último trimestre de 2015, com vistas à conclusão, no mais breve prazo possível, de um Acordo de Associação equilibrado, ambicioso, abrangente e benéfico para ambas as partes. 


\section{CONSIDERAÇÕES FINAIS}

Neste trabalho, argumentamos que o giro pós-neoliberal na América do Sul, sob a égide do neodesenvolvimentismo, não logrou, até agora, criar as condições para uma integração regional plena na América do Sul. Entretanto, pode-se falar na ampliação e no aprofundamento de aspectos da integração, mormente quanto à articulação política, com a criação da Unasul e de segurança com o CDS. Igualmente, na área social e comunitária, registram-se alguns avanços como a livre circulação de pessoas, dentre outras ações. Todavia, assim como no plano internacional, no plano regional, identifica-se um pacto igual entre desiguais, embora os condutores do processo da integração tentem atenuar essa situação com iniciativas como o Focem e o Banco do Sul.

O rumo da integração depara-se, também, com velhos e novos problemas e desafios que delineiam incertezas quanto ao lugar do Mercosul na política de integração do subcontinente, em particular face ao avanço da China nos mercados da região.

A integração regional da América do Sul depara-se, ainda, com a falta de uma liderança capaz de aglutinar os países da região em torno de um modelo de integração neodesenvolvimentista e pós-liberal. A maior liderança regional, o Brasil, além de não reunir condições de um líder estruturador inconteste, depara-se com divisões internas, principalmente a respeito de políticas econômicas relacionadas à exploração do petróleo do pré-sal, descoberto na Amazônia Azul, assim como outras riquezas minerais da região. Trata-se de produtos que são objeto de cobiça internacional, com o agravante de ser o petróleo a mais estratégica matéria-prima do setor energético, o que dá ideia das pesadas disputas partidárias em curso. Acrescente-se à questão do petróleo do pré-sal a probabilidade de o eixo de produção energética do país se deslocar para a costa leste, com mudanças substanciais em sua matriz energética e diminuição de demanda por gás de outros mercados da região. Em jogo está o modelo de inserção internacional do país, com possíveis impactos diretos em toda a região. Outras premissas de incerteza quanto ao rumo da integração são colocadas pelo fato de dois Estados Partes do Mercosul, além de outros da Costa do Pacífico, constarem na lista de países do TISA.

Se o giro à esquerda na América do Sul e sua política neodesenvolvimentista e de integração pós-liberal vão subsistir à renovada arrancada do ultraliberalismo capitaneada pelos Estados Unidos, a história da América Latina, inclusive a recente, não permite veleidades otimistas. Todavia novos atores estão no tabuleiro do xadrez da geopolítica dos dias atuais, a exemplo dos Brics e particularmente da China, a qual já se faz presente na região e pode significar alguma diferença no jogo em curso. Mas a que custo? Ou seja, que perfil de inserção internacional dos países da região emergirá num futuro próximo? Os países da região vêm-se, mais uma vez, diante do velho dilema - integração versus fragmentação. Quiçá a resposta do processo histórico não seja um giro à colonialidade do poder.

Recebido para publicação em 15 de outubro de 2015 Aprovado em 21 de novembro de 2015

\section{REFERÊNCIAS}

AMORIM, C. A Diplomacia do governo Lula. Aula Magna Senhor Ministro das Relações Exteriores no Instituto Rio Branco. Brasília, Resenha de Política Exterior, 10. abr. 2003.

AYERBE, L. F. (org.). Novas lideranças políticas e alternativas de governo na América do Sul. São Paulo: Unesp, 2008.

BATISTA JR, P. N. A América do Sul em movimento. Revista Economia Política, v. 28, n. 2, p. 226-238, 2008.

BIONDI, A. O Brasil privatizado: um balanço do desmonte do Estado. São Paulo: Geração Editorial, 2014.

BIRLE, P. Zwischen Integration und Fragmentierung: Regionale Zusammenarbeit in Lateinamerika. In: (Org.) Lateinamerika im Wandel. [em local ]: Nomos. $20 \overline{10 .}$ p. 75-98.

BOSCHI, R; GAITÁN, F. Intervencionismo estatal e políticas de desenvolvimento na América Latina. Caderno CRH: revista do Centro de Recursos Humanos da UFBA, Salvador, v. 21 , n. 53, p. 305-322, maio/ago. 2008. 
BRESSER. Novo Desenvolvimentismo: Uma Proposta para a Economia do Brasil. Nueva Sociedad. Especial em Português. 2010 Disponível em: http://www. bresserpereira.org.br/papers/2010/10.26. Brasil novo desenvolvimentismo-Nueva_Sociedad.pdf. 2010. Acessō em: $23 / 08 / 2012$.

. Assalto ao Estado e ao mercado, neoliberalismo e teoria econômica. Estudos Avançados, São Paulo, v. 23, n. 66, p. 7-23, [S.M], 2009

BUENO, C. O Barão do Rio Branco e o projeto da América do Sul. In: CARDIM, C. H.; ALMINO, J. (orgs.). Rio Branco, a América do Sul e a modernização do Brasil. Rio de Janeiro: EMC, 2002, p. 359-392.

CARNEIRO, R. Globalização e integração regional. Cadernos do Desenvolvimento. Rio de Janeiro, Centro Internacional Celso Furtado de Política para o Desenvolvimento, v. 3, n. 5, p. 43-80, 2008.

CASTRO, A. No espelho da China, 2007, mimeo.

CEPAL. América Latina y el Caribe y China Hacia una nueva era de cooperación económica. Santiago, 2015.

CERVO, A. L. América Latina no século XXI: da unidade à dispersão. In: Relações internacionais da América Latina. São Paulo: Saraiva, 2013, p. 233-268.

COSTA, F. Desenvolvimento do desenvolvimentismo: do socialismo utópico ao social-desenvolvimentismo. Textos para Discussão. IE/UNICAMP. Campinas, 2012, n. 206, p. 16 - 36, maio. 2012. Disponível em: www.eco.unicamp. $\mathrm{br} /$ docprod/downarq.php?id=3185\&tp=a. Acesso em 07.07.2015

DINIZ, E. O Contexto internacional e a retomada do debate sobre desenvolvimento no Brasil contemporâneso (2000/2010). Dados, Rio de Janeiro, v. 54, n. 4, p. 493 - 531. 2011 Disponível em: www.scielo.br/pdf/dados/v54n4/01. pdf . Acesso em 01.07.2015.

Desenvolvimento e Estado desenvolvimentista:

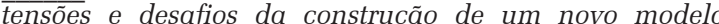
para o Brasil do século XXI. In: Revista de Sociologia e Política, Curitiba, v. 2, n. 47, p. 9-29, set. 2013. Disponível em: $\quad$ http://www.scielo.br/scielo.php?pid=S010444782013000300002\&script=sci_arttext. Acesso em $01 / 07 / 15$.

DUMÉNIL, G.; LÉVY, D. A Crise do neoliberalismo. São Paulo: Boitempo, 2014.

ESCUDÉ, C. Principios de realismo periférico. Una teoria Argentina y su vigencia ante el ascenso de China. Buenos ๑ Aires: Lumière, 2012.

ণ FERCHEN, M. As relações entre China e América Latina: impactos de curta ou longa duração?. Revista Sociologia e เి Política. 2011, vol.19, supl.1, p. 105-130.

เి FIORI, J. L. História, estratégia e desenvolvimento: para $\neg$ uma geopolítica do capitalismo. São Paulo: Boitempo. 2. 2014, 277p.

O Poder global e a nova geopolítica das nações. São

¿ FONSECA, P. C. D. Desenvolvimentismo: a construção do conceito. IPEIA 2013 Textos para Discussão. Brasília: ๙ IPEIA, p. 1-59, julho. 2015. Disponível em: http://

$\Rightarrow$ www.ipea.gov.br/portal/index.php?option $=$ com

$\therefore$ content\&view=article\&id=25801\&Itemid=383. Acesso 흘 em 05/07/15.

IVO, A. B. L. O paradigma do desenvolvimento: do mito s fundador ao novo desenvolvimento. Caderno $C R H$ : revista If do Centro de Recursos Humanos da UFBA, Salvador, v. 25, n. 65, p. 187-209, maio/ago. 2012.

JUNKIS, R. La expansión global de China y su impacto en América Latina. In: BACA, S. (org.). La expansión de China en América Latina. Ecuador: CELAEP, 2015, p. 13-53.
KATZ, F. J. Questionando as teorias da dependência e da financeirização. O Brasil na encruzilhada do desenvolvimento do capitalismo. São Paulo: Plêiade. 2011, $288 \mathrm{p}$.

KLEMI, A. M. M.; MENEZES, R. G. A resiliência do Mercosul: trajetória e lugar do bloco na integração regional. Disponível em: periodicos.unb.br/index.php/revistadoceam/article/ view/994. Acesso em 04.05.2014.

LAMOSO, L. P. "Neodesenvolvimentismo" brasileiro: implicações para a integração regional no âmbito do Mercosul. Sociedade e Natureza, Uberlândia, n. 3, p. 391404, set/dez. 2012. Disponível em: http://www.scielo.br/ pdf/sn/v24n3/v24n3a02.pdf . Acesso em: 05.04.2015.

LESBAUPIN, I. (Org.). O desmonte da nação: balanço do Governo FHC. Petrópolis, RJ: Vozes, 1999.

LIMA, M. R. S. de. Liderazgo regional en América del Sur: ¿tine Brasil un papel a jugar? In: LAGOS, R. (Org.) América Latina: ¿Integración o fragmentación? Buenos Aires: Edhasa, 2008, p. 89-114.

LULA DA SILVA, L. I. Discurso do Presidente da República no encerramento do seminário "Brasil-China: uma parceria de sucesso”. Xangai, 26. mai. 2004, p. 131.

MEDEIROS, C. A. de. Os dilemas da integração sulamericana. Cadernos do Desenvolvimento. Rio de Janeiro, Centro Internacional Celso Furtado de Política para o Desenvolvimento, v. 3, n. 5, p. 213-254. 2008.

MENEZES, R. G. Integração, imaginação e política externa: as bases do paradigma sul-americano? BJIR, Marília, v. 1, n. 3, p.482-497, Set/Dez. 2012.

MENZEL, U. Globalisierung versus Fragmentirung. Frankfurt am Main: Suhrkamp. 1998.

MERCOSUL. Comunicado Conjunto das Presidentas e dos Presidentes dos Estados Partes do MERCOSUL - Brasília, 17 de julho de 2015. Disponível em:

http://www.itamaraty.gov.br/index.php?option =com co ntent\&view $=$ article\&id $=10523$ :comunicado-conjuntodas-presidentas-e-dos-presidentes-dos-estadospartes-do-mercosul-brasilia-17-de-julho-de-2015\&catid $=42 \&$ lang $=$ pt-BR\&Itemid $=280$

MINISTÉRIO DAS RELAÇÕES EXTERIORES. Resenha de Política Exterior. 2004, v. 1. PRESIDÊNCIA DA REPÚBLICA. Casa Civil. Sub-Chefia para Assuntos Jurídicos. Decreto N. 5.969 de 21 de novembro de 2006. Disponível em: http:// www.planalto.gov.br/ccivil_03/_Ato2004-2006/2006/ Decreto/D5969.htm. Acesso em̄: 06.06.2015.

RODRIK, D. Estratégias de desenvolvimento para o novo século. In: ARBIX, G. et al. (Org.). Brasil, México, África do Sul, Índia e China. Diálogo entre os que chegaram depois. São Paulo: Edusp/Unesp, 2002, p. 43-78.

ROUSSEFF, D. Na cerimônia de encerramento do Seminário Empresarial Brasil-China: Para Além da Complementaridade. Pequim. 12 de abril de 2011. Disponível em: http:/www2.planalto.gov.br/acompanheo-planalto/discursos/discursos-da-presidenta/discursoda-presidenta-da-republica-dilma-rousseff-na-cerimoniade-encerramento-do-seminario-empresarial-brasil-chinapara-alem-da-complementaridade

RUSSEL, R; TOKATLIAN, J. G. Resistencia y cooperación: opciones estratégicas de América Latina frente a Estados Unidos. In: LAGOS, R. (Org.) América Latina: ¿Integración o fragmentación? Buenos Aires: Edhasa, 2008, p. 209-235.

El Lugar del Brasil en la politica exterior de la Argentina: la vision del otro. Buenos Aires: Fundo de Cultura, 2003. Desarrollo Econômico, v. 42, n. 167, oct./ dic. p. 405-428.

SALLUM JR., B. Estamos reorganizando o capitalismo brasileiro. Entrevista de Fernando H. Cardoso. Lua Nova, n. 39,1997 , p. 11-31 
SANAHUJA, J. A. Regionalismo post-liberal y multilateralismo em Sudamérica: El caso de UNASUR. Disponível em: http:/www.ieei-unesp.com.br/portal/wp-content/ uploads/2012/10/2012-Anuario-CRIES-1.pdf. Acesso em: 06.04.2015.

SANTOS, L. C. V. G. A América do Sul no discurso diplomático brasileiro. Revista Brasileira de Política Internacional, v. 48, n. 2, 2005, pp. 185-204.

SANTOS, M. Por uma outra globalização: do pensamento único à consciência universal. 5. ed. Rio de Janeiro: Record, 2001

SERBIN, A.; MARTÍNEZ, L.; RAMANZINI JR, H. (Orgs). El regionalismo "post-liberal" em América latina y el Caribe: nuevos actores, nuevos temas, nuevos desafios. Anuario de la Integración Regional de América Latina y el Gran Caribe 2012, Buenos Aires: CRIES, 2012, n. 9.
SPECK, K. Politische Integration der Ärmsten in ein politisches System auf Krücken? Brasilien unter Präsident Lula. In: BIRLE, P. (Org.) Lateinamerika im Wandel. [em local ]: Nomos. 2010. p. 117-137.

SOUZA, A. A Agenda internacional do Brasil. Rio de Janeiro: Campus, 2009.

VEIGA, P. M.; RÍOS, S. P. O regionalismo pós-liberal, na américa do Sul: origens, iniciativas e dilemas. Seire Comercio Internacional, CEPAl, Santiago de Chile, n. 82, p. 1-44, julio. 2007.

WIKILEAKS. Trade in Services Agreement. Disponível em: https://wikileaks.org/tisa/. Acessado em: 04.07.2015 


\section{BRAZIL AND MERCOSUL: direction of the integration in the logic of neodevelopment (2003-2014)}

\author{
Albene Miriam Menezes Klemi \\ Roberto Goulart Menezes
}

\section{LE BRÉSIL ET LE MERCOSUR: vers l'intégration dans la logique du néo-développement (2003- 2014)}

\author{
Albene Miriam Menezes Klemi \\ Roberto Goulart Menezes
}

Cet article analyse le processus d'intégration en Amérique du Sud, en fonction des prémisses du néo-développement mené par le Brésil pendant une période qui va de 2003 à 2014 . Ce virage à gauche est accompagné d'un souci de développement économique et de justice sociale, de la défense de l'intégration régionale dans le cadre des prémisses post-néolibérales, de l'insertion internationale avec un certain degré d'autonomie et d'un renforcement du rôle de l'Etat pour atteindre ces objectifs. Dans son approche, le thème prend aussi en considération la présence de la Chine dans la région et tout particulièrement son rapprochement avec l'Argentine et le Brésil. Il se veut d'apporter des éléments permettant un éclairage sur les questions qui suivent. Cette stratégie d'intégration menée par le Brésil et où la défense de l'intégration a un poids important, a-t-elle permis de l'intensifier? Et, quelle est la place de l'intégration dans ce "virage à gauche"? L'analyse se fait dans une perspective historique et se base sur des documents officiels et sur les publications spécialisées en la matière.

Keywords: Mercosul. Regional integration. Mot-clés: Mercosur. Intégration régionale. NéoNeodevelopment. Post-neoliberalismo. China. développement. Post-néolibéralisme. Chine. Brasil-Alemanha e as relações dos países da América Latina, com ênfase nos processos de integração. Publicações recentes: A resiliência do Mercosul: trajetória e lugar do bloco na integração regional, em coautoria com Roberto Goulart Menezes, in http://periodicos.unb.br/index.php/revistadoceam/article/ view/9947; Tensão política entre o Brasil e a Alemanha, o pulsar dos acontecimentos em 1938. Revista Múltipla, Brasília, v. 26, n. 34, p. 9-28, jun. 2013.

Roberto Goulart Menezes - Doutor em Ciência Política. Professor do Programa de Pós-Graduação em Relações Internacionais (PPGRI) do Instituto de Relações Internacionais da Universidade de Brasília e Coordenador do Curso de Graduação em Relações Internacionais. É coordenador do Núcleo de Estudos Latino-Americanos (NEL/IREL/UnB). Integra a coordenação da Rede de Pesquisa em Política Externa e Regionalismo - REPRI (UnB, Unesp, UFU e Unifesp). Entre os temas de pesquisa estão: Economia Política Internacional, Integração Sul-Americana, Relações Internacionais da América do Sul/América Latina, Política Externa Brasileira, Geopolítica, Cooperação Internacional e Desenvolvimento. Associado à ABRI (Associação Brasileira de Relações Internacionais) e à ABCP (Associação Brasileira de Ciência Política). Publicações recentes: The Brazilian strategy of integration and the Pacific Alliance America. The Quarterly of Latin American Economy and Trade, v. 17, p. 16-28, 2014; A Estratégia de integração regional brasileira e a Aliança do Pacífico. World citizen magazine, v. 2, p. 2-16, 2014; Lições da história: a ascensão da China e as relações Sul-Sul. Brazilian Journal of International Relations, v. 2, p. 418-425, 2013. 